\title{
A paradigm shift in the management of neovascular glaucoma
}

\author{
V Swetha E Jeganathan ${ }^{1,2 *}$ and David Wardrop ${ }^{3}$ \\ ${ }^{1}$ Department of Ophthalmology, University Hospital Ayr, Scotland, United Kingdom \\ ${ }^{2}$ University of Edinburgh, Scotland, United Kingdom \\ ${ }^{3}$ Department of Ophthalmology, Falkirk Community Hospital, Scotland, United Kingdom
}

\begin{abstract}
Neovascular glaucoma (NVG) secondary to proliferative diabetic retinopathy (PDR) is a potentially devastating condition. The commonest cause of treatment failure in NVG is underlying systemic disease progression. The underlying ischemia is often refractory to medical treatment. Surgical options have evolved to include Bevacizumab in the Ophthalmologist's armamentarium. Visual prognosis can be guarded in these patients who additionally have reduced life expectancy. Thus, early diagnosis and aggressive treatment is imperative to avert visual loss, and improve their prognosis. We present a case of NVG secondary to PDR which was challenging to treat. The patient adherent to his treatment plan and achieved unusually successful results, maintaining good vision.
\end{abstract}

\section{Introduction}

First documented in 1871, neovascular glaucoma (NVG) remains a potentially devastating condition, often refractory to medical treatment [1]. Surgical options have evolved to include Bevacizumab in the Ophthalmologist's armamentarium. Nevertheless, early diagnosis and aggressive treatment is imperative to avert visual loss.

\section{Reasons for patient selection}

We present a case of NVG secondary to proliferative diabetic retinopathy (PDR) which was challenging to treat. The patient adherent to his treatment plan and achieved unusually successful results, maintaining good vision.

\section{Case report}

\section{Medical and ophthalmic patient history}

A 64-year-old retired land agent with poorly controlled type 2 diabetes (HbA1c 10.7) was referred by the retinal screening services with bilateral non-PDR and clinically significant macular oedema in his right eye, requiring focal laser with good result. Seven months later, the patient had right phacoemulsification complicated by posterior capsule tear with sulcus lens placement. Visual acuity (VA) in the affected eye improved from 20/60 to 20/20 and his left was 20/20.

Our patient had a morbidly high body mass index, hypertension, hypercholesterolemia, peripheral vascular disease, peripheral neuropathy, osteoarthritis, and gastroesophageal reflux disease, for which he took Ramipril, Atenolol, Atorvastatin, Bendrofluamethiazide, Glimepiride, Aspirin and Cimetidine. He smoked 20 cigarettes daily for 30 years and quit in 1988. A more sedentary retirement lifestyle had resulted in worsening of his diabetes control and weight gain.

\section{Clinical investigations and management}

Six months following his cataract surgery, the patient presented with sudden onset severe right eye pain, redness, and decreased vision (Hand Movements). Examination revealed right conjunctival injection and corneal oedema. Rubeosis iridis was seen bilaterally, being more pronounced in his right eye. Intraocular pressures (IOP) were 67 and $15 \mathrm{mmHg}$, in right and left eyes respectively. Right fundus examination was limited due to corneal oedema and it appeared likely he had bilateral PDR. Initial treatment consisted of topical timolol, brinzolamide, latanoprost, dexamethasone, atropine and $500 \mathrm{mg}$ intravenous acetazolamide, followed by $250 \mathrm{mg}$ oral acetazolamide qds. The next day, his right VA improved to count fingers and the eye was comfortable with an IOP of $30 \mathrm{mmHg}$. Gonioscopy revealed a closed angle in the right eye, with neovascularisation of the iris (NVI) and angle (NVA) bilaterally. The working diagnosis was NVG secondary to PDR, with ocular ischaemic syndrome (OIS) as a differential diagnosis.

Urgent carotid Doppler ultrasound excluded occlusive disease. Fundus fluorescein angiography (FFA) revealed widespread retinal ischaemia bilaterally (Figures $1 \mathrm{a}$ and $1 \mathrm{~b}$ ). Due to severe retinal and iris ischaemia, the patient underwent several sessions of retinal pan-retinal photocoagulation (PRP), totalling 4,020 burns to the right eye and 4,800 to his left eye, allowing rubeosis regression.

The patient was adherent to medical therapy: topical iopidine, brimonidine, dexamethasone and followed-up closely. Nevertheless, his right IOP remained persistently elevated. He received intravitreal Bevacizumab $(1.25 \mu \mathrm{g} / 0.05 \mathrm{ml})$, followed by cyclodiode laser (17 burns X 1.5W X 1.5s) and a Mitomycin C trabeculectomy (Figure 2). The timeline is shown below (Figure 3). Additionally, he had multiple 5-fluorouracil (5FU) bleb needlings and a weeks course of serial subconjunctival injections. When his IOP exceeded $30 \mathrm{mmHg}$, Acetazolamide tablets were restarted. Although his best corrected VA improved to 20/30, his right IOP averaged at $21 \mathrm{mmHg}$, with active

Correspondence to: Dr. V. Swetha E. Jeganathan, Department of Ophthalmology, University Hospital Ayr, Dalmellington Road, Ayr KA6 6DX, Scotland, United Kingdom; Email: vswetha@ausdoctors.net

Received: April 01, 2016; Accepted: April 21, 2016; Published: April 25, 2016 


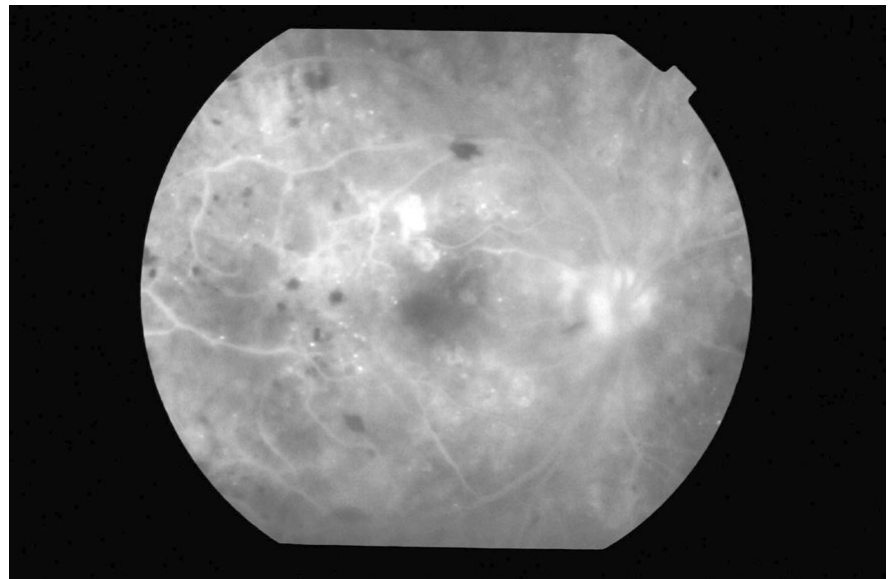

Figure 1a. Right eye showing areas of capillary dropout $(+)$.

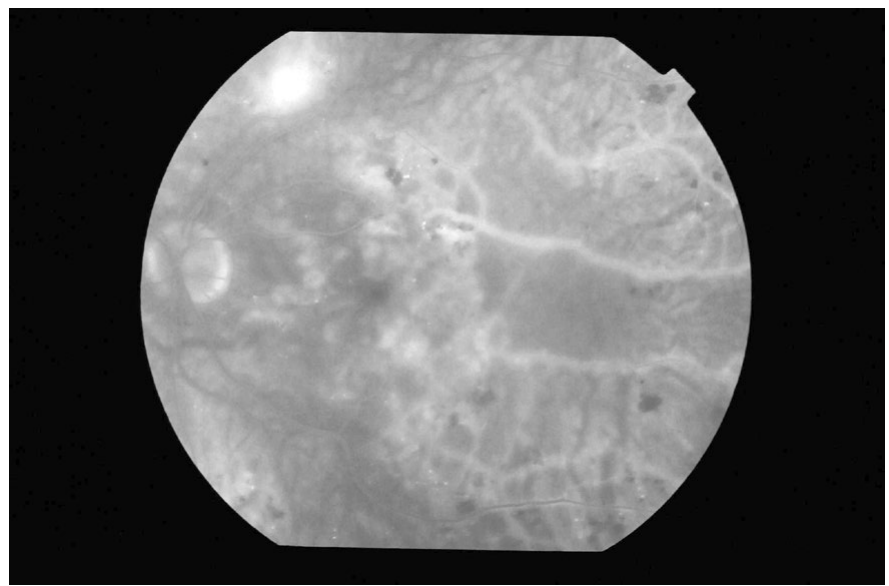

Figure 1b. Left eye showing areas of capillary dropout ( $\square$ ) and hard exudates (+)

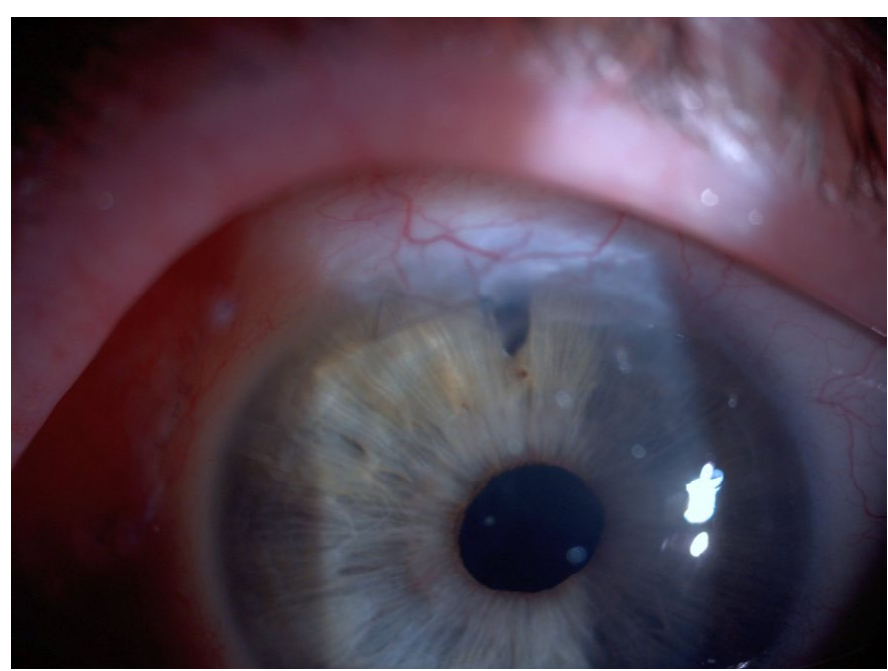

Figure 2. Mitomycin C augmented trabeculectomy.

NVI present. He subsequently received PRP augmentation prior to Ahmed valve implantation (Figure 4). At his most recent review (nine months following his initial acute presentation), his IOP remains stable $(16 \mathrm{mmHg})$ with regression of NVI (Figure 5).

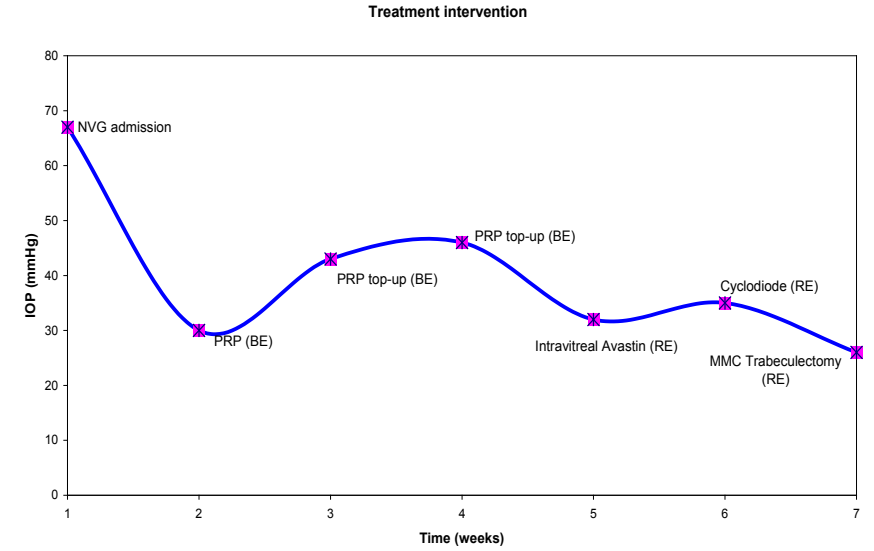

Figure 3. Timeline of treatment intervention with associated intraocular pressures of the right eye.

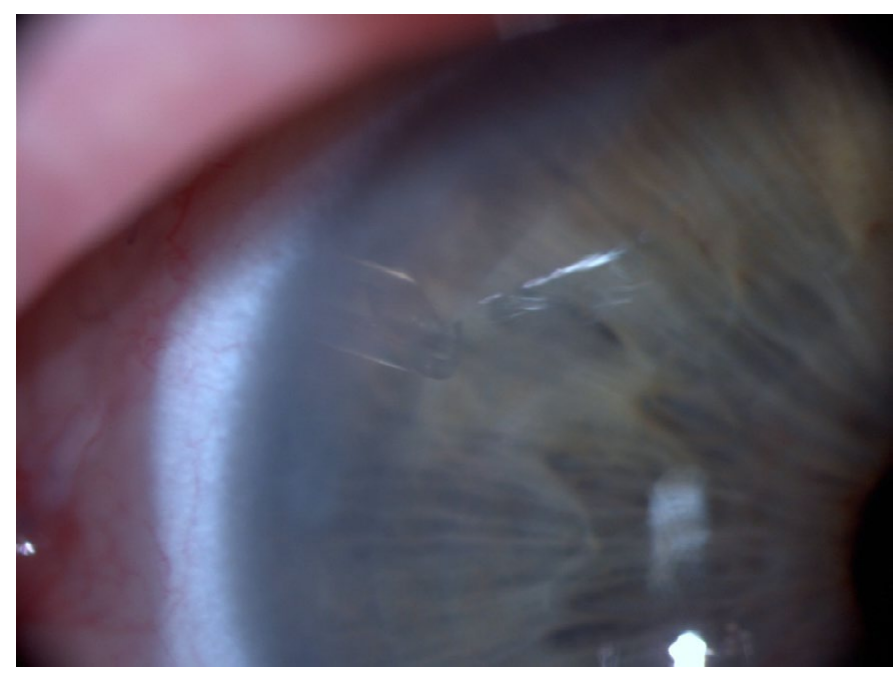

Figure 4. Implanted Ahmed valve (right eye).

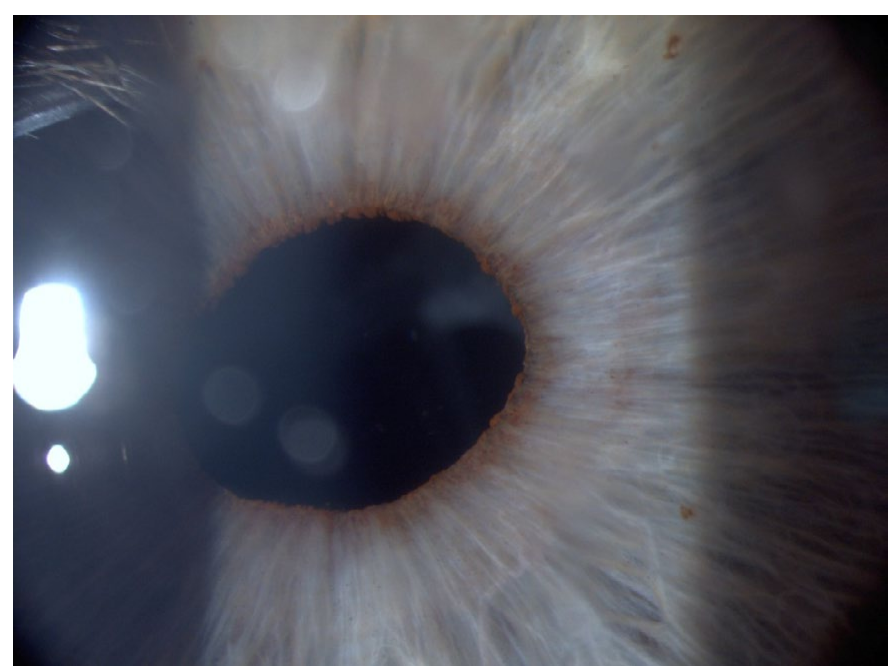

Figure 5. Rubeosis regressed (right eye). 


\section{Discussion}

\section{Pathophysiology of NVG in PDR}

Diabetes accounts for more than $30 \%$ of NVG cases [2]. The development of DR results in capillary occlusion and reduced perfusion, with retinal ischaemia triggering a cascade of events commencing with hypoxia to the Muller cells leading to angiogenesis (Figure 6) [3].

Typically, vascular endothelial growth factor (VEGF) and Angiopoietin-2 levels are in equilibrium with pigment epitheliumderived growth factor (PEDF), an anti-angiogenic factor. However, when the equilibrium is switched in favor of VEGF and Angiopoietin-2, activation, proliferation, and migration of endothelial cells and pericytes occur, inducing angiogenesis. NVI and NVA ultimately lead to the formation of fibrovascular membranes, which maybe invisible on gonioscopy but can ultimately obstruct the trabecular meshwork or associated peripheral anterior synechiae resulting in secondary glaucoma. In our patient, the posterior capsules tear during his cataract surgery, maybe the presumed mechanism behind the diffusion of VEGF into the anterior chamber.

\section{Clinical investigations}

NVG is a clinical diagnosis, which is straightforward in advanced cases, but recognising early disease can be difficult. Systemic and ocular associations with NVG may include diabetes, retinal vascular occlusive diseases, OIS, retinal detachment, ocular neoplasia and uveitis. Detailed examination of the iris and angle of the anterior chamber should be performed before pupil dilatation. A complete ocular examination of both eyes particularly of the posterior segment will provide the answer to the etiology of neovascularization Careful gonioscopy is recommended to detect early NVA and anterior synechiae. FFA may help to detect occult neovascularization [4].

\section{Management options}

The treatment of NVG is approached through the following 4 stages that reflect the progression of disease: prophylaxis, early, advanced and end-stage. Managing the underlying systemic disease is critical to ameliorate both NVI and IOP. Adequate IOP control can be especially challenging in NVG and often requires a combination of medical and surgical interventions, depending visual potential. Addressing risk factors and retinal ischemia can minimize subsequent

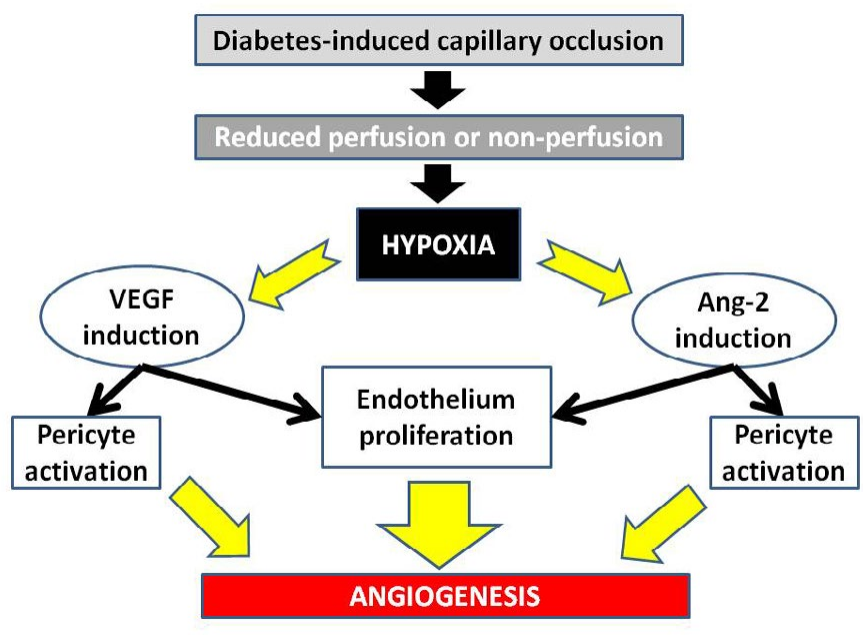

Figure 6. Pathogenesis of angiogenesis in diabetes leading to NVG. neovascularization.

\section{General treatment}

Diabetes patients require a thorough systemic workup and appropriate intervention to prevent further complications. Tight glycemic control is vital as the onset of NVG in diabetics is associated with glucose control. The Diabetes Control Complications Trial found a $24 \%$ incidence of NVG over 9 years amongst the standard versus $8 \%$ in the intensively treated group [5].

\section{Medical therapy}

Treatment selection to lower IOP depends upon the stage of NVG. Elevated IOP maybe due to compromised trabecular meshwork function. Aqueous suppressants (beta blockers, alpha-agonists, carbonic anhydrase inhibitors) may be effective in NVG when used in combination. With long-term use of oral carbonic anhydrase inhibitors, close monitoring of electrolytes is important especially in those with concomitant renal disease. Initial prostaglandin use may help, but their effectiveness maybe impaired if a fibrovascular membrane obstructs the uveal outflow path [6]. Furthermore, prostaglandins may exacerbate ocular inflammation. Adjunctive topical steroid treatment may control inflammation and improve surgical outcome. Cycloplegic agents can relieve discomfort, inflammation and decrease IOP. Despite these measures, failure of medical therapy alone is the norm especially in advanced NVG [6].

\section{Panretinal photocoagulation (PRP)}

Currently, laser treatment is regarded as the method of choice for prevention and treatment of NVG in diabetics. The Diabetic Retinopathy Study guidelines recommend 1,200 to 1,500 burns to be applied to the peripheral retina [7]. If PDR exists, then complete PRP is recommended. Extensive PRP is indicated for severe ischemic retinopathy, as in our case. Adequate treatment of retinal ischemia with PRP can help stabilize IOP and reduce neovascularization of the anterior segment [8]. Ohnishi et al. reported regression of rubeosis in $68 \%$ of patients as well as normalization of IOP in $42 \%$ of patients treated with PRP. In NVG secondary to PDR, 1,200 to 1,600 burns produce rubeotic regression in $70.4 \%$, whereas 400 to 650 burns suffice for $37.5 \%$ [9].

The presence of profuse neovascularization presents a significant risk for intra- and post-operative hemorrhage. As PRP requires several weeks to exert its effects, it is ideally performed urgently ( 2 or 3 weeks prior to surgery) to reduce the risk of hyphema and bleb failure, assuming adequate corneal clarity [10]. Furthermore, PRP itself can lead to increased IOP from cilio-choroidal effusions, necessitating close follow-up [11].

\section{Anti-VEGF therapy}

The identification of VEGF has helped NVG management to evolve. Intravitreal Bevacizumab (Avastin; Genetech, Inc., South San Francisco, CA) is now used as the initial treatment of NVG patients with PDR, with a randomized controlled trial confirming its efficacy in regressing neovascularization and reducing IOP [12]. Rubeotic regression with reduced capillary permeability in FFA can be seen within 24 hours, with clinical evidence at day 2 to 7 [13]. Bevacizumab has a half-life of 3 days and rubeotic regression lasts approximately 4 to 8 weeks, allowing time for adequate PRP [14]. The anti-VEGF agent can additionally potentiate the effects of PRP [15]. Moreover, Bevacizumab is beneficial in trabeculectomy augmented by Mitomycin $\mathrm{C}$ and 


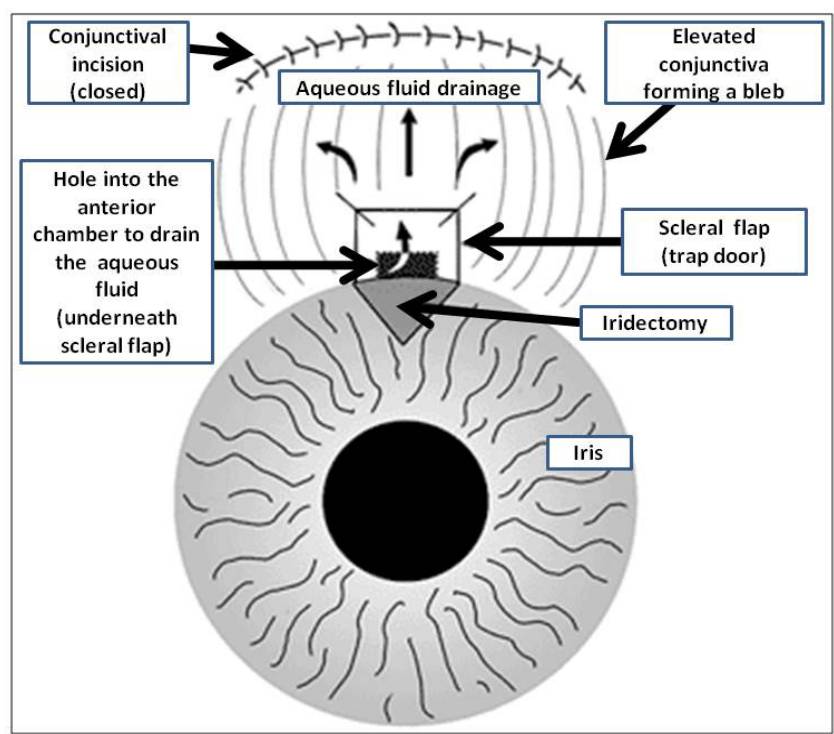

Figure 7. Standard trabeculectomy (schematic representation).

improves the success rate of aqueous shunts $[16,17]$. The procedure is relatively safe, despite occasional reports of glaucoma, cataract and central retinal artery occlusion [18,19]. Further hazards of anti-VEGF treatment include hyphema and long term IOP elevation with serial injections [20]. The long term effectivity of Bevacizumab in controlling IOP is uncertain.

\section{Surgery}

Surgery is considered in NVG when the elevated IOP cannot be controlled conservatively. Although the success rate is much lower in patients with NVG, in comparison to the general population, prognosis tends to be better in PDR compared to CRVO and OIS [21]. Headto head comparison of evidence-based literature is often difficult due to different aetiologies of NVG, baseline patient characteristics and outcome measures. Furthermore, there is paucity of prospective, randomised controlled trials.

\section{Trabeculectomy}

Trabeculectomy (Figure 7) offers the benefit of attaining lower postoperative IOP compared to aqueous shunts and is preferred in a quiet eye with a view for adequate PRP or possible anti-VEGF treatment [22]. Postoperatively, the patient should be frequently examined to confirm adequate aqueous humour flow and manipulations may include bleb massage, suture release, topical steroids, 5-FU injections and bleb needling. NVG with standard trabeculectomy (without antifibrotics) has a significant failure rate (up to $80 \%$ ), most likely due to fibrovascular proliferation and bleb scarring [23]. However with adjunctive antimetabolites, the IOP has been shown to be successfully lowered in a larger patient population [24]. Although trabeculectomy augmented with mitomycin $\mathrm{C}$ or 5 -FU has shown good short term results, its success rate declines to $28 \%$, five years post-operatively, with patients with type 1 diabetes of 50 years or younger having extremely poor prognosis [25]. To date, the surgical success has been reported to be $68 \%$ over 3 years, utilizing 5 -FU subconjunctival injections postoperatively [25]. Scleral patch graft may be used in cases of fullthickness scleral defect encountered during bleb revisions [26]. Despite all efforts, it has to be accepted that a subgroup of trabeculectomies will fail.

\section{Aqueous shunts}

Glaucoma drainage implants (aqueous tube shunts) were previously considered as the last resort in refractory glaucoma. Today, the surgery is used as a primary surgical option in NVG as an alternative to trabeculectomy. The Tube versus Trabeculectomy trial revealed that drainage devices had a higher success rate than trabeculectomy with Mitomycin C, during 3 years follow-up [27]. Additionally, aqueous shunts are more forgiving of intra- and post-operative bleeding or fibrinous reaction. However, implanting the device can be technically challenging particularly in a rubeotic eye and ideally tube shunts should be placed as far posterior as possible (i.e., in the sulcus of pseudophakes or in the pars plana following vitrectomy) to prevent occlusion by fibrovascular membrane and corneal decompensation [28]. The Ahmed implant (FP7, New World Medical, Rancho Cucamonga, CA) is a pressure sensitive, unidirectional valve that prevents early postoperative hypotony, flat anterior chambers, and choroidal effusions, compared to alternate drainage devices [29]. The success rates for patients with NVG range from 22 to $97 \%$ and similar among different aqueous tube shunts [30].

\section{Cyclophotocoagulation}

Cycloablation to reduce aqueous humour formation was the first surgical procedure for IOP reduction. Currently, diode laser transscleral cyclophotocoagulation (TCP) is in favour; however endoscopic cyclophotocoagulation is gaining popularity [31]. IOP reduction occurs by selective partial thermal photodestruction of the ciliary body. This option was previously reserved for blind, painful eyes or for patients who were poor surgical candidates. However, TCP is now indicated in functional eyes with advanced glaucoma (including NVG) with uncontrolled IOP despite maximal therapy, refractory to conventional laser or surgery [32]. TCP has shown efficacy in reducing IOP from 44 to $21.2 \mathrm{mmHg}$ in short/medium term but treatment may need to be repeated [33]. Agarwal and colleagues found a $40 \%$ decrease in IOP to less than $19 \mathrm{~mm} \mathrm{Hg}$ in eyes with NVG with the contact approach, whereas in the noncontact approach, out of 27 eyes with NVG, only $15 \%$ achieved satisfactory IOP control [34]. Yildrim et al. compared contact TCP with the Ahmed implant in NVG showing similar results between the 2 groups, with success rates at 2 years of $61.2 \%$ and $59.3 \%$ respectively [36].

TCP is a relatively safe procedure [36]. However, TCP misalignment can result in iris or lens damage. Over-treatment can cause local conjunctival burns or even vitreous hemorrhage due to ciliary body disruption. An IOP rise greater than baseline may occur in up to $30 \%$ eyes within a few hours of treatment. Visual reduction $\geq 2$ lines occurs (in up to $47 \%$ ), with complete loss of vision, hypotony (17.6\%) and phthisis bulbi (0.5 to $2 \%)$ a possibility [37].

\section{Future therapeutic options}

Various novel pharmacological agents that modulate the angiogenesis cascade now offer great potential as therapeutic agents for NVG [38,39]:

- $\quad$ Pigment epithelium derived factor (PEDF) overexpression inhibits retinal inflammation and neovascularization in mouse models.

- VEGF trap (EYLEA, Bayer), a modified soluble VEGF receptor analog binds VEGF more tightly than all other anti-VEGF therapies.

- $\quad$ Small interfering RNA (siRNA) targeting VEGF expression 
has been downregulated in vitro and in vivo, leading to inhibition of retinal neovascularization.

\section{Conclusion}

NVG secondary to PDR is certainly a challenge to manage with a high failure rate. Adequate IOP control can be difficult to achieve and needs lifelong monitoring. The underlying ischemia can be resistant to treatment. Visual prognosis is often guarded with patients additionally having reduced life expectancy. The commonest cause of treatment failure in NVG is underlying systemic disease progression. Early recognition of risk factors is important for a favorable outcome.

Patients with NVG must be educated about their condition, importance of adherence and to co-manage their health. So far, IOP control has been achieved. However, the long tem IOP control needs to be established before any conclusions drawn to his successful management.

\section{Lessons learned}

- The management of NVG is complex and the underlying pathology (i.e. diabetes) needs to be addressed aggressively.

- $\quad$ The patient's IOP needs to be monitored closely to identify any significant change early.

- If medical treatment, PRP and intravitreal Bevacizumab therapy are inadequate, consider the benefits of aqueous tube shunts early.

\section{Acknowledgements}

With thanks to Dr Alan Rotchford (Consultant Ophthalmologist, Tennent Institute of Ophthalmology, Gartnavel General Hospital, Glasgow). V. Swetha E. Jeganathan, Finalist Alcon glaucoma case awards, Hemel Hempsted, September 2012.

\section{References}

1. Gartner S, Henkind P (1978) Neovascularization of the iris (rubeosisiridis). Surv Ophthalmol 22: 291-312. [Crossref]

2. Jeganathan VS, Wang JJ, Wong TY (2008) Ocular associations of diabetes other than diabetic retinopathy. Diabetes Care 31: 1905-1912. [Crossref]

3. Jeganathan VS (2011) Anti-angiogenesis drugs in diabetic retinopathy. Curr Pharm Biotechnol 12: 369-372. [Crossref]

4. Ishibashi S, Tawara A, Sohma R, Kubota T, Toh N (2010) Angiographic changes in iris and iridocorneal angle neovascularization after intravitrealbevacizumab injection.Arch Ophthalmol 128: 1539-1545. [Crossref]

5. [No authors listed] (1995) Progression of retinopathy with intensive versus conventional treatment in the Diabetes Control and Complications Trial. Diabetes Control and Complications Trial Research Group. Ophthalmology 102: 647-661. [Crossref]

6. Shazly TA, Latina MA (2009) Neovascular glaucoma: etiology, diagnosis and prognosis. Semin Ophthalmol 24: 113-121. [Crossref]

7. Bressler NM, Beck RW, Ferris FL 3rd (2011) Panretinal photocoagulation for proliferative diabetic retinopathy. $N$ Engl J Med 365: 1520-1526. [Crossref]

8. Fujioka S, Karashima K, Saito Y (2009) Differences of ocular circulation in eyes with proliferative diabetic retinopathy after panretinal photocoagulation with and without rubeosisiridis. Nihon Ganka Gakkai Zasshi 113:11-15. [Crossref]

9. Ohnishi Y, Ishibashi T, Sagawa T (1994) Fluorescein gonioangiography in diabetic neovascularisation. Graefes Arch Clin Exp Ophthalmol 232: 199-204. [Crossref]

10. Little HL (1985) Treatment of proliferative diabetic retinopathy. Long-term results of argon laser photocoagulation.Ophthalmology 92: 279-283. [Crossref]

11. Alkawas AA, Shahien EA, Hussein AM (2010) Management of neovascular glaucoma with panretinal photocoagulation, intravitrealbevacizumab, and subsequent trabeculectomy with mitomycin C. J Glaucoma 19: 622-626. [Crossref]
12. Yazdani S, Hendi K, Pakravan M, Mahdavi M, Yaseri M (2009) Intravitrealbevacizumab for neovascular glaucoma: a randomized controlled trial. J Glaucoma 18: 632-637. [Crossref]

13. Beutel J, Peters S, Lüke M, Aisenbrey S, Szurman P, et al. (2010) Bevacizumab as adjuvant for neovascular glaucoma. Acta Ophthalmol 88: 103-109. [Crossref]

14. Iliev ME, Domig D, Wolf-Schnurrbursch U, Wolf S, Sarra GM (2006) Intravitrealbevacizumab (Avastin) in the treatment of neovascular glaucoma. $\mathrm{Am} \mathrm{J}$ Ophthalmol 142: 1054-1056.[Crossref]

15. Ciftci S, Sakalar YB, Unlu K, Keklikci U, Caca I, et al. (2009) Intravitrealbevacizumab combined with panretinal photocoagulation in the treatment of open angle neovascular glaucoma. Eur J Ophthalmol 19: 1028-1033. [Crossref]

16. Saito Y, Higashide T, Takeda H, Ohkubo S, Sugiyama K (2010) Beneficial effects of preoperative intravitrealbevacizumab on trabeculectomy outcomes in neovascular glaucoma. Acta Ophthalmol 88: 96-102. [Crossref]

17. Eid TM, Radwan A, el-Manawy W, el-Hawary I (2009) Intravitrealbevacizumab and aqueous shunting surgery for neovascular glaucoma: safety and efficacy. Can J Ophthalmol 44: 451-456. [Crossref]

18. Higashide T, Murotani E, Saito Y, Ohkubo S, Sugiyama K (2012) Adverse events associated with intraocular injections of bevacizumab in eyes with neovascular glaucoma. Graefes Arch Clin Exp Ophthalmol 250: 603-610. [Crossref]

19. Meyer CH, Ziemssen F, Heimann H (2008) Intravitreal injection. Monitoring to avoid postoperative complications. Ophthalmologe 105: 143-155. [Crossref]

20. Tseng JJ, Vance SK, Della Torre KE, Mendonca LS, Cooney MJ, et al. (2012) Sustained increased intraocular pressure related to intravitrealantivascular endothelial growth factor therapy for neovascular age-related macular degeneration. J Glaucoma 21: 241247. [Crossref]

21. Fernández-Vigo J, Castro J, Macarro A (1997) Diabetic iris neovascularization. Natural history and treatment. Acta Ophthalmol Scand 75: 89-93. [Crossref]

22. Dahan E, Ben Simon GJ (2011) An augmented trabeculectomy for neovascular glaucoma. Ophthalmic Surg Lasers Imaging 42: 196-201. [Crossref]

23. Mietz H, Raschka B, Krieglstein GK (1999) Risk factors for failures of trabeculectomies performed without antimetabolites. Br J Ophthalmol 83: 814-821. [Crossref]

24. Takihara Y1, Inatani M, Fukushima M, Iwao K, Iwao M, et al. (2009) Trabeculectomy with mitomycin $\mathrm{C}$ for neovascular glaucoma: prognostic factors for surgical failure. $\mathrm{Am}$ J Ophthalmol 147: 912-918, 918.[Crossref]

25. Tsai JC, Feuer WJ, Parrish RK 2nd, Grajewski AL (1995) 5-Fluorouracil filtering surgery and neovascular glaucoma. Long-term follow-up of the original pilot study. Ophthalmology 102: 887-892. [Crossref]

26. Au L, Wechsler D, Spencer F, Fenerty C (2009) Outcome of bleb revision using sclera patch graft and conjunctival advancement. J Glaucoma 18: 331-335. [Crossref]

27. Gedde SJ1, Schiffman JC, Feuer WJ, Herndon LW, Brandt JD, et al. (2009) Three-year follow-up of the tube versus trabeculectomy study. Am J Ophthalmol 148: 670-684. [Crossref]

28. Olmos LC, Lee RK (2011) Medical and surgical treatment of neovascular glaucoma. Int Ophthalmol Clin 51: 27-36. [Crossref]

29. Sarkisian SR Jr (2009) Tube shunt complications and their prevention. Curr Opin Ophthalmol 20: 126-130. [Crossref]

30. Minckler DS, Francis BA, Hodapp EA, Jampel HD, Lin SC, et al. (2008) Aqueous shunts in glaucoma: a report by the American Academy of Ophthalmology. Ophthalmology 115: 1089-1098. [Crossref]

31. Pastor SA, Singh K, Lee DA, Juzych MS, Lin SC, et al. (2001) Cyclophotocoagulation: a report by the American Academy of Ophthalmology. Ophthalmology 108: 2130-2138. [Crossref]

32. Rotchford AP, Jayasawal R, Madhusudhan S, Ho S, King AJ, et al. (2010) Transscleral diode laser cycloablation in patients with good vision. Br J Ophthalmol 94: 1180-1183. [Crossref]

33. Tzamalis A, Pham DT, Wirbelauer C (2011) Diode laser cyclophotocoagulation versus cyclocryotherapy in the treatment of refractory glaucoma. Eur J Ophthalmol 21: 589596. [Crossref]

34. Agarwal HC, Gupta V, Sihota R (2004) Evaluation of contact versus non-contact diode laser cyclophotocoagulation for refractory glaucomas using similar energy settings. Clin Experiment Ophthalmol 32: 33-38. [Crossref] 
35. Yildirim N, Yalvac IS, Sahin A, Ozer A, Bozca T (2009) A comparative study between diode laser cyclophotocoagulation and the Ahmed glaucoma valve implant in neovascular glaucoma: a long-term follow-up. J Glaucoma 18:192-196. [Crossref]

36. Spencer AF, Vernon SA (1999) "Cyclodiode": results of a standard protocol. $B r J$ Ophthalmol 83: 311-316. [Crossref]

37. LinP, WollsteinG, Glavas IP, SchumanJS(2004)Contacttransscleralneodymium:yttrium- aluminum-garnet laser cyclophotocoagulation Long-term outcome. Ophthalmology 111:2137-2143. [Crossref]

38. Jiang J, Xia XB, Xu HZ, Xiong Y, Song WT, et al. (2009) Inhibition of retinal neovascularization by gene transfer of small interfering RNA targeting HIF-1alpha and VEGF.J Cell Physiol 218: 66-74. [Crossref]

39. Jeganathan VS (2011) Novel pharmacotherapies for diabetic retinopathy: current and future perspectives.Curr Pharm Biotechnol 12: 336. [Crossref]

Copyright: C2016 Jeganathan VSE. This is an open-access article distributed under the terms of the Creative Commons Attribution License, which permits unrestricted use, distribution, and reproduction in any medium, provided the original author and source are credited. 